\title{
Application of direct steam injection system to minimize browning of white radish (Raphanus sativus) broth during sterilization
}

\author{
Tae Hoon Ham, Won Byong Yoon \\ (Dept. of Food Sci. and Biotechnology, Kangwon National University, Chuncheon, Gangwon-do 24341, South Korea)
}

\begin{abstract}
Direct steam injection (DSI) was applied to minimize the quality changes of white radish (Raphanus sativus) broth during sterilization. This study compared the degree of browning of white radish broth from a retort sterilization system and a DSI system. The quality changes after thermal treatments, such as retorting and DSI, were evaluated by Lab color values, the browning index (BI) and sensory evaluation. As the volume of the retort pouch increased, the thermal processing time increased. Significant increases of $a$ and $b$ values, color difference and BI were observed. Unlike the retort sterilization, the DSI treatment showed no significant differences in color properties of the radish broth with a wide range of sterilization temperature. The highest sensory score among the DSI treated samples was observed at the lowest sterilization temperature $\left(125^{\circ} \mathrm{C}\right)$. The results demonstrated that the DSI treatment showed a higher stability in the quality associated with the browning reaction, such as the color indices and BI because the DSI process rapidly increased the temperature of the radish broth by transferring the latent heat of steam to the fluid.
\end{abstract}

Keywords: direct steam injection (DSI), retort, sterilization, quality, browning, white radish broth, sensory evaluation DOI: $10.25165 /$ j.ijabe.20171006.3350

Citation: Ham T H, Yoon W B. Application of direct steam injection system to minimize browning of white radish (Raphanus sativus) broth during sterilization. Int J Agric \& Biol Eng, 2017; 10(6): 210-220.

\section{Introduction}

From ancient times, Asian countries have used broth for flavoring soups and stews. Generally, the broth is prepared with various ingredients, such as white radish, kelp, anchovy, and meat through prolonged boiling. The broth traditionally provides a base taste for many foods, which contributes to the enhancement of deep and strong flavors in food. As meat or bone is boiled in water for a long time, constituents like albumin, protein, peptides and amino acids dissolve into the water ${ }^{[1]}$. Radish has been utilized as a fundamental producer of flavor in soup with meat, fish, and fish cakes. Radish broth has a browning response due to the thermal

\section{Received date: 2017-03-17 Accepted date: 2017-06-25}

Biographies: Won Byong Yoon, Professor, research interests: food process engineering, Email: wbyoon@kangwon.ac.kr.

*Corresponding author: Won Byong Yoon, Professor, research interests: food process engineering, Dept. of Food Sci. and Biotechnology, Kangwon National University, Chuncheon, Gangwon-do 24341, S. Korea. Tel/Fax: 82-33-250-6459/82-33259-5565, Email: wbyoon@kangwon.ac.kr. processing that is a part of broth production. Andi et al. ${ }^{[2]}$ reported that the main mechanism of radish browning is polyphenol oxidase catalyzed oxidation of polyphenol compounds in white radish. However, a high temperature treatment $\left(>90^{\circ} \mathrm{C}\right)$ inactivates the polyphenol oxidase during heat treatment ${ }^{[3]}$. Thus, the browning reaction of radish broth at a high temperature is mainly due to Maillard reaction ${ }^{[4]}$. The browning response of radish implies that heat sterilization importantly influences on the quality of radish broth in the commercial mass production.

Processed food packaged in pouches or cans generally uses a retort method for the sterilization, which is a batch type of thermal process that heats a product packaged in a container with steam or water at high temperatures and pressures. Although the retort method assures commercially safe food products, as microorganisms and spores are inactivated, its disadvantages include generation of off-flavors and destruction of pigments or bioactive components, such as polyphenol anti-oxidant ingredient ${ }^{[5-9]}$. 
Since the commercial value of the processed food depends largely on taste, nutritional value and safety, an optimized processing is essential to produce commercial food products that are safe while maintaining quality during sterilization. The size of packages of retorted food products can be decided upon the demanding of its final users. For consumers, the size of the retort product is small, while, for industrial food services, a bulk size product is needed for efficiency. Sterilization time should be controlled by the size of the package to maintain a consistent degree of sterilization. Thus, the sterilization time is different for a small package product and a bulk packaged product. When the sterilization process is designed without considering the size of package, the safety and the quality of the products may not be uniformly controlled due to either over-sterilization or under-sterilization ${ }^{[7,8,10]}$. Several studies have addressed that the unintended changes in color and flavor of vegetables, such as carrots, white beans, green beans, mushrooms and pumpkins, were associated with over- or under-sterilization due to its package size ${ }^{[9,11-13]}$. Hong et al. ${ }^{[10]}$ reported that the degree of sterilization and the quality of products were significantly affected by its size and shape. When a high-temperature sterilization system is applied to produce radish broth, the degree of browning must be considered. Especially, as the size of the package and the sterilization time increase, the degree of browning is dramatically increased, and it may cause lowering the consumer acceptability.

Direct steam injection (DSI) is a continuous sterilization process in which high temperature steam $\left(100^{\circ} \mathrm{C}-160^{\circ} \mathrm{C}\right)$ is directly injected into the fluid passing through a pipe. In the DSI system, the latent heat of steam is directly delivered to the fluid in a very short time. DSI could be an innovative food processing technology to replace retort sterilization while overcoming its drawbacks. Due to the characteristics of DSI, high production rate is achieved. The temperature increase is faster due to the direct inflow of latent heat. The most prominent advantage of using DSI is maintaining the quality of products since the target temperature is attained so quickly ${ }^{[14-18]}$. When suitable operating conditions are provided, DSI can consistently sterilize liquids with the same quality regardless of the size of the packages.

Thermal processing should be determined based on the kinetic characteristics of the microbial inactivation and the quality changes of products, which are functions of the thermal processing temperature and time ${ }^{[19-21]}$. When the temperature sensitivity of quality degradation during thermal processing is lower than the rate of thermal inactivation of microorganisms, the quality changes can be minimized. Thus, a fast heating rate is usually required to minimize thermal degradation. Application of DSI for sterilization of food products could achieve such an optimal sterilization process because the thermal processing time to reach a target sterilization temperature is extremely short and also there is no temperature gradient in the products. A temperature gradient is inevitably associated with a batch type of thermal processing (i.e., a retort process) or in an indirect heating (i.e., a heat exchanger). Also, the DSI process has a big advantage when sterilizing a fluid containing particles with high viscosity. When the retort process is conducted with a fluid with high viscosity, the heat transfer rate becomes slower due to a low convection heat transfer and eventually, an extended processing time is required. This extended thermal processing time usually causes a degradation of quality and nutrition in the product. In contrast, because of the high shear rate of steam flow in the DSI process, the multiphase of flow with steam and high viscosity flow is well mixed. Thus, even for a highly viscous fluid, the temperature increasing is fast.

The purposes of this study are: 1) to estimate the processing time achieving target $F_{0}$-value for different pouch volumes, 2) to determine the flow rate and processing time for different processing temperature of DSI, and 3) to compare the effect of the retort and DSI processes on the degree of browning and sensory score of radish broth after sterilization to establish an optimum processing system for radish broth.

\section{Materials and Methods}

\subsection{Materials}

White radish (Raphanus sativus) was purchased in a 
local market in Chuncheon, South Korea. Since radish broth is traditionally made by boiling radish juice, radish juice was used to make radish broth for this study. The radish was stored at $4^{\circ} \mathrm{C}$ and at $55 \%$ relative humidity and tested in 2 weeks after purchasing. The radish juice was prepared by the following procedures: the radish sample was cut to a uniform size $(5 \mathrm{~mm} \times 5 \mathrm{~mm} \times 50 \mathrm{~mm})$ after elimination of peels and then smashed by a mixer (Hanil, HMF-3260S, Seoul, S. Korea) operating for $20 \mathrm{~s}$. The smashed radish juice was diluted to $10 \%$ (w/v) in distilled water. The $10 \%(\mathrm{w} / \mathrm{v})$ of radish juice was used for this study, and the concentration (10\%) was determined based on the solid concentration of commercial radish broth. Retort and DSI were applied to the diluted juice to produce the radish broth.

\subsection{Retort sterilization}

A retort (SR-240, Tomy, Tokyo, Japan) was used to produce the radish broth. In order to prevent the effect of the difference in shape, the retort pouch was produced with a certain dimension, such as width:depth:height (0.70:1.00:0.07). The pouch volumes were $5000 \mathrm{~mL}$ $(320 \mathrm{~mm} \times 460 \mathrm{~mm} \times 34 \mathrm{~mm}), 2500 \mathrm{~mL}(256 \mathrm{~mm} \times$ $368 \mathrm{~mm} \times 27 \mathrm{~mm}), 1250 \mathrm{~mL}(203 \mathrm{~mm} \times 292 \mathrm{~mm} \times$ $21.5 \mathrm{~mm}), 750 \mathrm{~mL}(122 \mathrm{~mm} \times 175 \mathrm{~mm} \times 13 \mathrm{~mm})$, and $500 \mathrm{~mL}(79 \mathrm{~mm} \times 114 \mathrm{~mm} \times 8.5 \mathrm{~mm})$. The retort pouch was composed of polyester (12.5 $\mu \mathrm{m}$ of thickness), aluminum foil $(15 \mu \mathrm{m})$ and polypropylene $(75 \mu \mathrm{m})$.

An adequate sterilization process for a low acid food, defined as $12 \mathrm{log}$ reduction of proteolytic Clostridium botulinum type A spores, is usually achieved at $121.1^{\circ} \mathrm{C}$ for 2.5-3 $\mathrm{min}^{[22-24]}$. However, in practice, $F_{0}$-values of 6-7 min are conducted for commercial products ${ }^{[23,24]}$. The minimal required $F_{0}$-values for sterilization as a function of the $\mathrm{pH}$ for low acid food products are reported $^{[22]} . \quad F_{0}$-value of $3 \mathrm{~min}$ showed an insufficient degree of sterilization for several processed foods ${ }^{[25]}$. Therefore, in this study the target degree of sterilization was set for $F_{0}$-value $6 \mathrm{~min}$. In order to calculate a suitable thermal process time to attain the target $F_{0}$-value of $6 \mathrm{~min}$, the temperature changes at various heights at the center of the pouch during the retort process were monitored using a wireless temperature sensor (Ellab, TrackSense Pro, Norfolk, UK). The location showing the lowest temperature was set as a cold point and used to determine the degree of sterilization as $F_{0}$-value. Coldest spot was defined by the location showing the lowest temperature at various heights at the center of the pouch. The height of the pouch was divided into four equal parts to make five points. The temperature at the second, third, and fourth points of the five points was measured. The locations of measurement were measured at points corresponding to $0.25,0.5$ and 0.75 of the pouch height as shown in Figure 1. The location was scaled for various size of pouch based on the simplified rectangular geometry. The depth, width and height of the pouch were denominated with $\mathrm{a}, \mathrm{b}$ and $\mathrm{c}$, respectively. The locations used to measure the temperature were coordinated as follows: 1 ) bottom: $0.5 \mathrm{a}$, $0.5 \mathrm{~b}$ and $0.25 \mathrm{c}, 2)$ center: $0.5 \mathrm{a}, 0.5 \mathrm{and}, 0.5 \mathrm{c}$, and 3 ) top: $0.5 \mathrm{a}, 0.5 \mathrm{~b}$ and $0.75 \mathrm{c}$. The heights measured the temperature of each pouch were as follows: 1) $8.5 \mathrm{~mm}$, $17 \mathrm{~mm}$ and $25.5 \mathrm{~mm}$ in $5000 \mathrm{~mL}$, 2) $6.75 \mathrm{~mm}, 13.5 \mathrm{~mm}$ and $20.25 \mathrm{~mm}$ in $2500 \mathrm{~mL}, 3) 5.38 \mathrm{~mm}, 10.75 \mathrm{~mm}$ and $16.13 \mathrm{~mm}$ in $1250 \mathrm{~mL}, 4) 3.25 \mathrm{~mm}, 6.5 \mathrm{~mm}$ and $9.75 \mathrm{~mm}$ in $750 \mathrm{~mL}$, and 5) $2.13 \mathrm{~mm}, 4.25 \mathrm{~mm}$ and $6.38 \mathrm{~mm}$ in $500 \mathrm{~mL}$. The $F_{0}$-value was calculated by Equation $(1)^{[18]}$ :

$$
F_{0}=\Delta t \sum 10^{\frac{T_{i}-121}{z}}
$$

where, $t$ indicates a thermal processing time and $T_{i}$ indicates the temperature of fluid at a thermal processing time step $i$. The time step of temperature measurement was $50 \mathrm{~s}$ in total processing time of $4500 \mathrm{~s}$. This time step sufficiently to represent the temperature profile of the entire processing time. The $D$-value is the time required to kill $90 \%$ of microorganisms. The $z$-value is the number of degrees the temperature has to be increased to achieve a tenfold reduction in the $D$-value. The $z$-value ware set as $10^{\circ} \mathrm{C}$ based on the thermal destruction

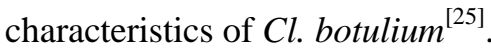

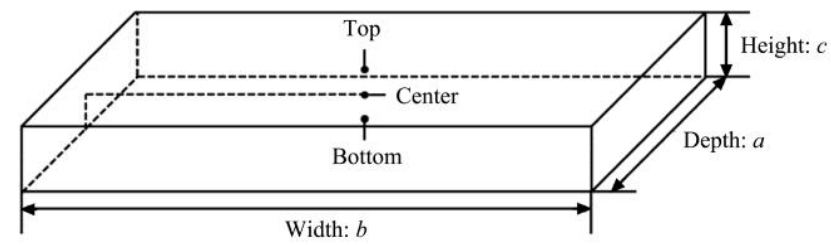

Figure 1 Location of temperature measurement in retort sterilization 


\subsection{DSI}

Injecting steam into the radish juice was carried out using a commercial DSI system (SilverLine ${ }^{\circledR}$, Hydro-Thermal Corp., Waukesha, WI, USA). The DSI system has two infusion type heaters to inject the steam into the fluid. Figure 2a presents a schematic of the mixing of steam and fluid; the side and the bottom view of the DSI system with the dimension of the pipe including the fluid flow are schematically shown in Figure $2 b$. The speed of inflow of fluid being sterilized was maintained consistently using a pump (DS-R40FW, Daesung Pump Co., Ltd., Seoul, S. Korea). The steam pressure was maintained as $4.75 \times 10^{5} \mathrm{~Pa}$. In this study, the target temperature of the fluid for sterilization was $125^{\circ} \mathrm{C}, 130^{\circ} \mathrm{C}$ and $135^{\circ} \mathrm{C}$, and the temperature of the inlet flow was $35^{\circ} \mathrm{C}$. The DSI system can be divided into three sections: 1) from the fluid inlet to the first steam injection (1), 2) from the first steam injection to the second steam injection (2), and 3) from the second steam injection to product outlet (3) (Figures 2a and 2b). All the sections were well insulated to maintain the flow temperature. The inner diameter of the pipe was $0.054 \mathrm{~m}$ and the length of each section was $1.68 \mathrm{~m}, 2.47 \mathrm{~m}$ and $2.51 \mathrm{~m}$, respectively. In each section, the temperature was measured by a temperature sensor attached in the middle of each section ( $b$ and $c$ in Figure 2b). The residence time $(\mathrm{mm})$ was calculated based on the volume flow rate and the length of sections using Equation (2):

$$
\text { Residence time }=\frac{\text { Area } \times \text { Length }}{\text { Volume flow rate }} \div 60
$$

where, the area is the cross-sectional area of pipe $\left(\mathrm{m}^{2}\right.$, $6.45 \times 10^{-4} \mathrm{~m}^{2}$ ) and the length is the total length of three sections $(\mathrm{m})$.

The concentration of the radish broth prepared by the DSI system must consider the amount of the condensation water produced by the phase transition of the steam injected to the radish broth. The quantity of steam was calculated by an energy balance through Equation (3):

$$
\begin{aligned}
& \int_{0}^{t} V_{p} \cdot \rho_{p} d t \cdot\left(T_{\text {target }}-T_{\text {inlet }}\right) \cdot C p_{p}=\int_{0}^{t} V_{s} \cdot \rho_{s} d t . \\
& \left(T_{\text {steam }}-T_{\text {target }}\right) \cdot C p_{s}+\int_{0}^{t} V_{s} \cdot \rho_{s} d t \cdot L_{s}
\end{aligned}
$$

where, $V$ indicates volume flow rate $\left(\mathrm{m}^{3} / \mathrm{s}\right) ; \rho$ is density $\left(\mathrm{kg} / \mathrm{m}^{3}\right) ; C p$ is specific heat $(\mathrm{kJ} / \mathrm{kg} \cdot \mathrm{K}) ; L$ is latent heat
$(\mathrm{kJ} / \mathrm{kg})$, and $T$ is temperature (K), Subscripts $p$ and $s$ indicate product and steam, respectively. Time $t$ is defined as the residual time from the start of steam injection to the outlet of DSI. $T_{\text {target }}, T_{\text {steam }}$ and $T_{\text {inlet }}$ indicate the target temperature, steam temperature and the temperature of inlet flow, respectively. The temperature of injected steam was at $150^{\circ} \mathrm{C}$ and the latent heat $(L)$ was calculated as $2257.06 \mathrm{~kJ} / \mathrm{kg}$, and the specific heat of water and steam was calculated as $4.19 \mathrm{~kJ} / \mathrm{kg} \cdot \mathrm{K}$ and $1.41 \mathrm{~kJ} / \mathrm{kg} \cdot \mathrm{K}$, respectively. The density of water and steam used were $987.99 \mathrm{~kg} / \mathrm{m}^{3}$ and $0.5975 \mathrm{~kg} / \mathrm{m}^{3}$, respectively ${ }^{[26]}$. In this study, specific heat of a product was assumed to be the specific heat of water due to its high water content

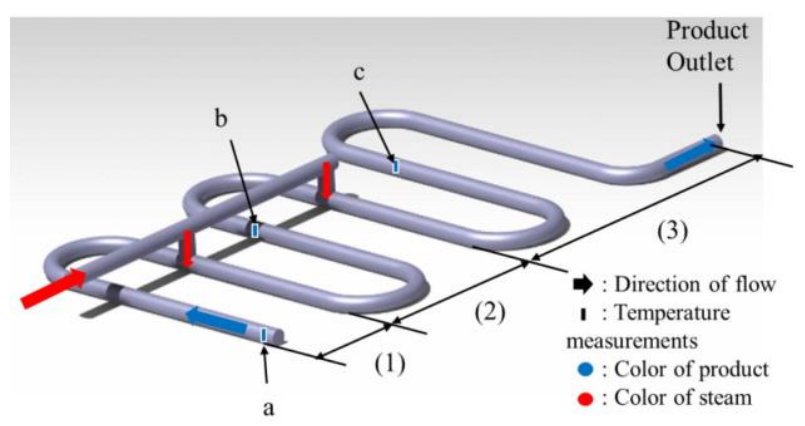

a. Schematic presentation of direct steam injection system

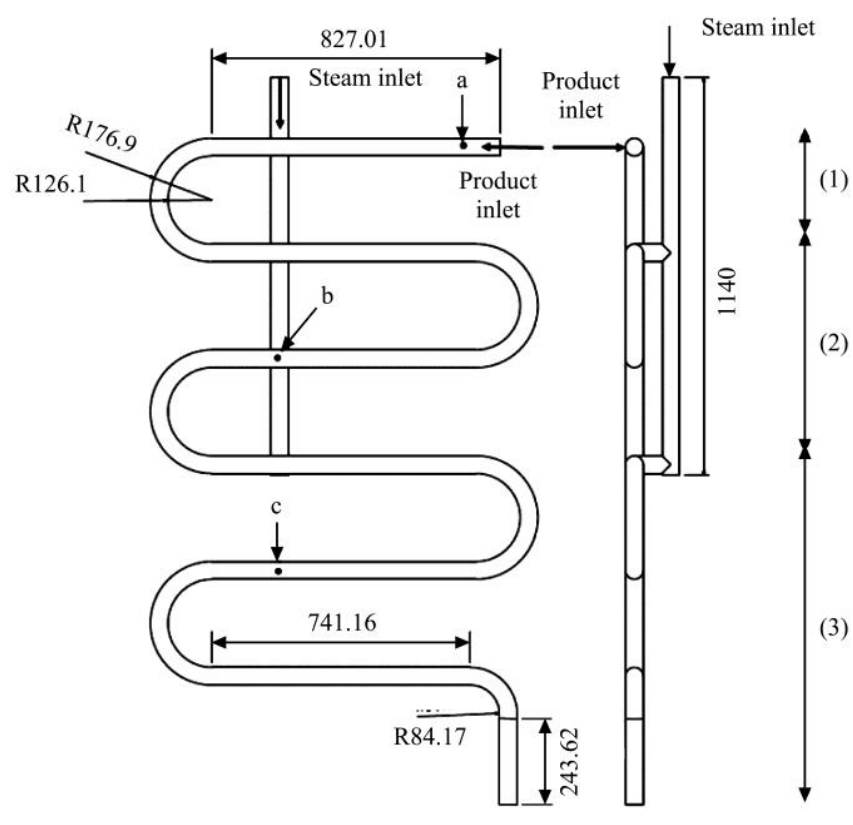

b. Bottom and side views

Note: The locations of infusion heaters are indicated by the vertical arrows in the red color. The fluid temperature at the inlet, between two steam injection, and after the final steam injection were measured at a, b and c, respectively. The final temperature of the fluid was measured at $c$.

Figure 2 Diagram of the direct steam injection system

To achieve the target $F_{0}$-value, the residence time was controlled by adjusting the flow rate. Based on the 
assumption that the flow temperature immediately increases after the steam injection and the temperature maintains consistently in each section during thermal processing, the $F_{0}$-value of the fluid passing through the DSI system was calculated by Equation (1). The immediate increase in temperature after the steam injection was assumed because the viscosity of radish broth was low and the velocity of the steam injected through infuser was high. Viscosity for the radish broth was measured using a viscometer (LVDV-II+, Brookfield Engineering, Middleborough, MA, USA), calibrated at $20^{\circ} \mathrm{C}$ with standard fluid. The viscometer measured fluid viscosity at $50-1000 / \mathrm{s}$ of shear rate and at $20^{\circ} \mathrm{C}$ of temperature. The viscosity measurements were carried out using spindle LV1. For viscosity measurements, $1.5 \mathrm{~mL}$ of radish broth was loaded on the viscometer. The mass flow rate of steam at the infuser was calculated based on the mass balance (Equation (3)). The flow of steam through the infuser passes through the 119 small holes of the infuser (the diameter of one hole $=1 \mathrm{~mm}$ ) (Figure 3). The velocity $(\mathrm{m} / \mathrm{s})$ of the steam was calculated by Equation (4).

$$
\text { velecity }=\frac{\text { mass flow rate }}{\text { density } \times \text { Area of holes }}
$$

To obtain the target $F_{0}$-value, the volume flow rate of product $\left(\mathrm{m}^{3} / \mathrm{s}\right)$ in the system was consistently maintained in each temperature condition $\left(0.00003 \mathrm{~m}^{3} / \mathrm{s}\right.$ at $125^{\circ} \mathrm{C}$, $0.00010 \mathrm{~m}^{3} / \mathrm{s}$ at $130^{\circ} \mathrm{C}$, and $0.00031 \mathrm{~m}^{3} / \mathrm{s}$ at $135^{\circ} \mathrm{C}$ ).

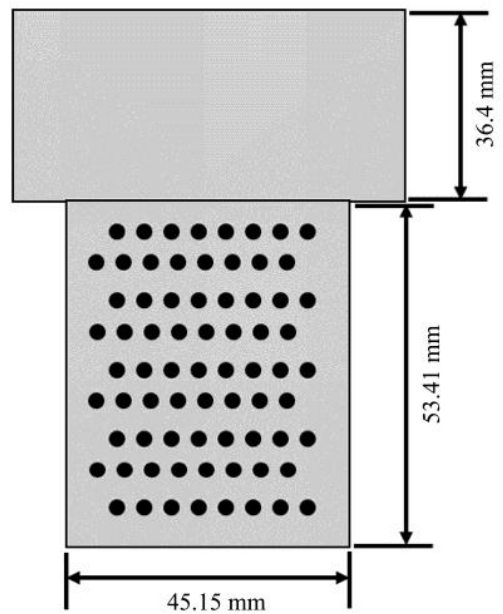

Figure 3 Schematic diagram of the infuser attached in the direct steam injection system

\subsection{Browning index (BI)}

The color index before and after sterilization was measured. After sterilization, $20 \mathrm{~g}$ of radish broth was sampled and immediately cooled to $5^{\circ} \mathrm{C}$ by placing it in a cooler. The color index of radish broth was measured using a colorimeter (CR-300, Minolta, Osaka, Japan). L (whiteness or brightness/darkness), $a$ (redness/greenness), and $b$ (yellowness/blueness) were used to obtain the color index to evaluate the degree of browning. Color index of the white board used for the calibration was $L=93.6$, $a=0.3135, b=0.3196$. Each sample was measured in triplicate. The color difference $(\Delta E)$ by the size of retort pouch and sterilization process was calculated by Equation (5):

$$
\begin{gathered}
\Delta E=\sqrt{\left(L_{0}-L\right)^{2}+\left(a_{0}-a\right)^{2}+\left(b_{0}-b\right)^{2}} \\
B I=\frac{[100(x-0.31)]}{0.17}
\end{gathered}
$$

The BI was calculated by Equation (6) ${ }^{[27]}$ :

where, $L, a$ and $b$ are each color indices of each treatment; $L_{0}, a_{0}$ and $b_{0}$ indicate the color indices of unsterilized radish broth. The $x$ in Equation (6) is defined as:

$$
x=\frac{a+1.75 L}{5.645 L+a-3.012 b}
$$

\subsection{Sensory evaluation}

Fifty members of a trained panel including males and females aged in their $20 \mathrm{~s}$ to their $50 \mathrm{~s}$ conducted the sensory evaluation. The evaluation of radish broth was done after three days of production and radish broth was equilibrated to $20^{\circ} \mathrm{C}$ prior to serving to the panel members. Color, flavor, odor, texture and overall preference of radish broth was evaluated on a 7-point hedonic scale $(1=$ dislike extremely, $4=$ moderate, $7=$ like extremely $)^{[28]}$. Every sample was stored at room temperature before the evaluation, and put in a $50 \mathrm{~mL}$ cup marked with a random three-digit number. A spoon was supplied to each panelist and water was provided to wash their mouth between evaluations. For each session, the panelists evaluated three to five samples; the mean value of the sensory score (color, flavor, odor, texture and overall preference) was used in the analysis.

\subsection{Statistical analysis}

Using SPSS 22.0 (SPSS Inc., Chicago, IL, USA), in order to analyze the difference between the samples, one-way analysis of variance (ANOVA) was used. Tukey test was used for the significance analysis $(p<0.05)$. 


\section{Results and Discussion}

\subsection{Retort sterilization depending on the size of pouch}

The temperature profiles for the different pouch volumes are presented in Figure 4a. As the pouch volume increased, the heat penetration rate decreased. The time to reach the target temperature of $121^{\circ} \mathrm{C}$ was $90.0 \mathrm{~min}, 75.0 \mathrm{~min}, 60.8 \mathrm{~min}, 43.3 \mathrm{~min}$ and $26.7 \mathrm{~min}$ for the $5000 \mathrm{~mL}, 2500 \mathrm{~mL}, 1250 \mathrm{~mL}, 750 \mathrm{~mL}$ and $500 \mathrm{~mL}$ pouch, respectively. This result indicated that the come-up-time (CUT) to target temperature decreased with the decreasing of the pouch volume. The result is similar to the result from Koo et al. ${ }^{[29]}$ in that the rate of temperature increase was slower as the volume of curry-containing pouches increased. As the CUT increased in larger pouches (Figure 4a), the total amount of heat added to radish broth increased. The CUT increase indicates that the temperature rise near the cold point is slow during heat treatment. Therefore, over-sterilization might occur near the interior wall of the pouch.

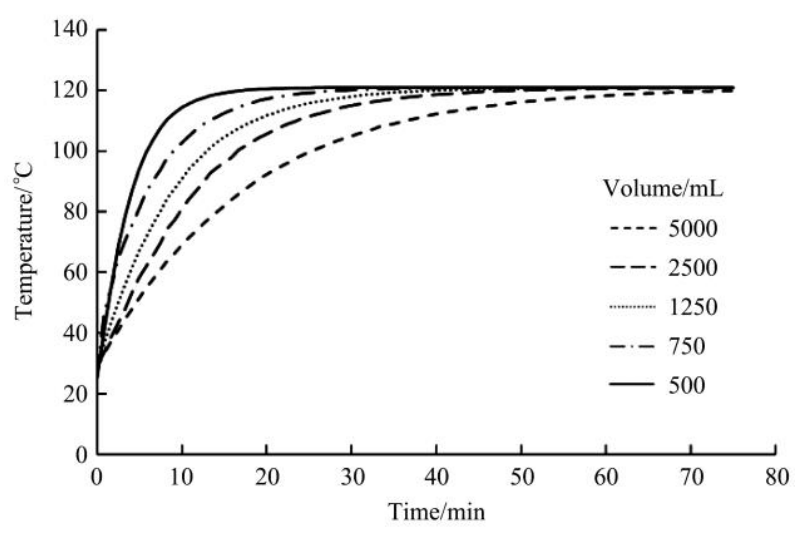

a. Temperature

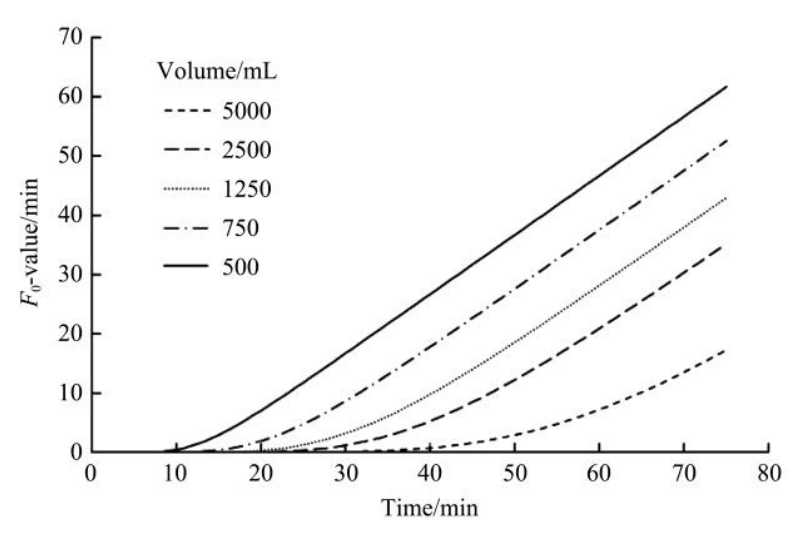

b. Lethality

Figure 4 Profiles of the retort processed white radish broth using different pouch volumes
The $F_{0}$-value at different sizes of pouches was calculated (Figure $4 \mathrm{~b}$ ). As the thermal processing time increased, the target $F_{0}$-value $(6.0 \mathrm{~min})$ was achieved. But, as the pouch volume increased, the thermal processing time to reach at the target $F_{0}$-value was significantly increased. The thermal process time, i.e., the time to reach target $F_{0}$-value, is displayed in Table 1 . As shown in Figure $4 \mathrm{~b}$ and Table 1 , the target $F_{0}$-value was achieved during CUT for all treatments. The increased thermal process time observed for large volume pouches might result in degraded broth quality, since the broth was exposed for a longer time at a temperature range that could accelerate chemical reactions, such as the browning reaction. Richard compared the thermal processing time depending on the can size in a simulation; sterilization time increased as the can size increased ${ }^{[30]}$. The size dependence of thermal processing time has been reported by others ${ }^{[5,7,8]}$; the collective prior and present results are the same.

Table 1 Processing time of the retort treatment for the white radish broth with different pouch volumes

\begin{tabular}{cc}
\hline Volume/mL & Processing time/min \\
\hline 5000 & $57.28 \pm 2.03^{\mathrm{a}}$ \\
2500 & $40.39 \pm 1.88^{\mathrm{b}}$ \\
1250 & $34.84 \pm 1.54^{\mathrm{c}}$ \\
750 & $26.71 \pm 1.22^{\mathrm{d}}$ \\
500 & $18.85 \pm 1.56^{\mathrm{e}}$ \\
\hline
\end{tabular}

Note: Mean value of three independent measurements \pm SD. Significant differences between treatment are indicated by different letter (ANOVA, $p<0.05$ ).

\subsection{DSI}

To verify the immediate increase of temperature after the steam injection, the viscosity of the fluid and the velosity of the steam passing through the infuser were measured and estimated, respectively. The viscosity of radish broth was represented in Figure 5. As shown in Figure 5, the viscosity of the radish broth was very low and showed a Newtonian fluid. The velocity of the steam passing through the $1^{\text {st }}$ infuser at $125^{\circ} \mathrm{C}, 130^{\circ} \mathrm{C}$, and $135^{\circ} \mathrm{C}$ were $4.96 \mathrm{~m} / \mathrm{s}, 5.18 \mathrm{~m} / \mathrm{s}$ and $5.38 \mathrm{~m} / \mathrm{s}$, respectivley, and that of the $2^{\text {nd }}$ infuser were $4.07 \mathrm{~m} / \mathrm{s}$, $4.36 \mathrm{~m} / \mathrm{s}$ and $4.73 \mathrm{~m} / \mathrm{s}$, respectively. These results indicated that the viscosity and the velocity of steam passing through the infusers were sufficient to produce a turbulent flow near the infuser. This is in agreement with many previous studies. Innings et al. ${ }^{[31]}$ reported 
that the steam was always condensed at the equilibrium temperature and the turbulence created in the condensation zone mixed the hot condensate. Therefore, the steam injection promptly heated the product. Additonally, van Asselt et al. ${ }^{[17]}$ also reported the immediate increase of temperature after the steam injection with milk. Therefore, in the present study, the flow pattern near each infuser might be turbulent, so it was assumed that the temperature of the fluid was promptly increased after the steam injection.

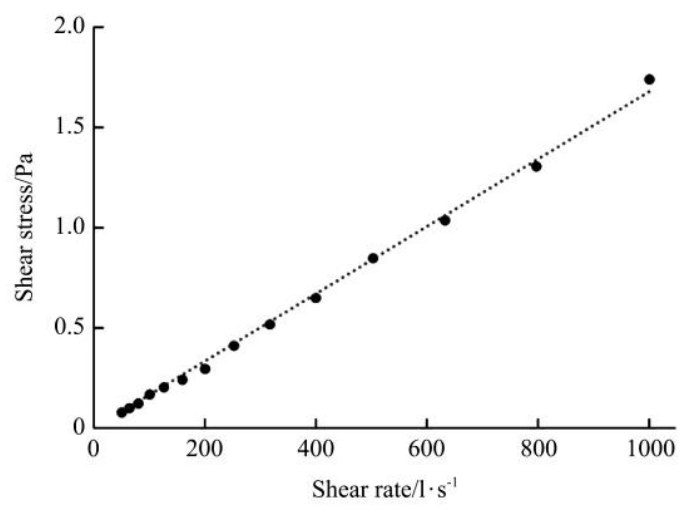

Figure 5 Viscosity of the radish broth at 50-1000/s of shear rate

To evaluate the $F_{0}$-value of DSI, the temperature in each section was measured and the residence time at each section was calculated based on the length, diameter and flow rate of radish broth (Table 2). When the target temperature was $125^{\circ} \mathrm{C}$, the temperature in the first section where the steam was not injected was $36^{\circ} \mathrm{C}$, the temperature in the second section where the first steam injection took place was $86.60^{\circ} \mathrm{C}$, and the temperature in the third section where the second steam injection was conducted was $125.50^{\circ} \mathrm{C}$. When the target temperature was higher $\left(130^{\circ} \mathrm{C}\right)$, the temperatures in the second and the third section were increased by $2.1{ }^{\circ} \mathrm{C}$ and $4.5^{\circ} \mathrm{C}$, respectively. For the target temperature of $135^{\circ} \mathrm{C}$, the temperatures were increased by $1.9^{\circ} \mathrm{C}$ and $5^{\circ} \mathrm{C}$, respectively. $F_{0}$-values in the first and second sections showed a small value $(<0.01)$, which might not significantly influence the achievement of the target $F_{0}$-value (6). The significant contribution to the degree of sterilization was performed in the third section after the second steam injection to the radish broth. The $F_{0}$-values from all three DSI operating conditions were higher than the target value $\left(F_{0}\right.$-value $\left.=6 \mathrm{~min}\right)$. The thermal process time from the DSI were $6.80 \mathrm{~min}$,
$2.24 \mathrm{~min}$ and $0.72 \mathrm{~min}$ at $125^{\circ} \mathrm{C}, 130^{\circ} \mathrm{C}$ and $135^{\circ} \mathrm{C}$, respectively. It was obvious that the thermal process time from the DSI was much shorter than those from the retort process. The DSI showed 0.36-fold, 0.12-fold and 0.04-fold process time compared to the retort process, since the shortest thermal process time obtained from the retort process was $18.85 \mathrm{~min}$. This result clearly demonstrated that the DSI provided a higher degree of sterilization within a short time. Several prior studies showed that the application of steam injection to a liquid food markedly and rapidly increased the temperature of the fluid. Milk was treated with DSI; a computer simulation for the transient temperature of fluid revealed a rapid increase of milk temperature immediately after the steam injection ${ }^{[17]}$. Karayannakidis et al. ${ }^{[32]}$ used the steam injection system to hydrolyze the squid protein and compared the efficiency with a conventional steam jacket reactor. DSI system showed a better performance in terms of energy consumption and the reaction rate of squid protein hydrolysis compared to those obtained from a conventional steam jacket reactor.

Table 2 Lethality of the direct steam injection system at each

\begin{tabular}{ccccc}
\multicolumn{5}{c}{ section } \\
\hline \multirow{2}{*}{ Section } & Temperature $/{ }^{\circ} \mathrm{C}$ & Residence time/min & $F_{0}$-value \\
\hline \multirow{2}{*}{$125^{\circ} \mathrm{C}$} & 2 & 36.0 & 1.72 & $0.01>$ \\
& 3 & 86.6 & 2.52 & $0.01>$ \\
& 1 & 125.5 & 2.56 & 7.20 \\
\hline \multirow{2}{*}{$130^{\circ} \mathrm{C}$} & 2 & 36.0 & 0.57 & $0.01>$ \\
& 3 & 130.7 & 0.83 & $0.01>$ \\
\hline & 1 & 36.0 & 0.84 & 6.70 \\
\hline $135^{\circ} \mathrm{C}$ & 2 & 90.6 & 0.18 & $0.01>$ \\
& 3 & 135.0 & 0.27 & $0.01>$ \\
& & & 0.27 & 6.84
\end{tabular}

\subsection{Color changes after the retort process}

Changes in color of radish broth after the retort process were evaluated according to the pouch volume. All the samples were collected immediately after the target $F_{0}$-value was reached. The color values depending on the volume are shown in Table 3 . The $L$ value, representing the whiteness, showed no significant difference according to the pouch volume. The $a$ value, representing the color red, showed a tendency to decrease as the pouch volume decreased. Especially, the $a$ value at $500 \mathrm{~mL}$ was significantly lower than those of $5000 \mathrm{~mL}$ and others. However, the $a$ value from $750 \mathrm{~mL}$ to 
$2500 \mathrm{~mL}$ showed no significant difference. It implied that a longer thermal processing time associated with a larger volume pouch influenced the color changes of radish broth. This became more obvious when the $b$ values, representing the color yellow, were compared. The $b$ value significantly increased as the pouch volume increased, which demonstrated that a longer thermal processing time observed from a larger pouch provided enough reaction time to generate the browning reaction from the radish broth. Based on the results, the $b$ value is the most sensitive value for the browning of radish broth.

Table 3 Lab color value of the white radish broth from different pouch volumes

\begin{tabular}{cccc}
\hline & \multicolumn{3}{c}{ Color value } \\
\cline { 2 - 4 } Volume $/ \mathrm{mL}$ & $L$ & $a$ & $b$ \\
\hline 5000 & $88.28 \pm 1.00^{\mathrm{a}}$ & $0.80 \pm 0.05^{\mathrm{a}}$ & $4.27 \pm 0.18^{\mathrm{a}}$ \\
2500 & $88.75 \pm 0.53^{\mathrm{a}}$ & $0.64 \pm 0.08^{\mathrm{b}}$ & $3.11 \pm 0.10^{\mathrm{b}}$ \\
1250 & $87.78 \pm 0.59^{\mathrm{a}}$ & $0.61 \pm 0.05^{\mathrm{b}}$ & $2.76 \pm 0.08^{\mathrm{c}}$ \\
750 & $88.27 \pm 0.69^{\mathrm{a}}$ & $0.56 \pm 0.06^{\mathrm{b}}$ & $2.32 \pm 0.08^{\mathrm{d}}$ \\
500 & $88.93 \pm 0.19^{\mathrm{a}}$ & $0.46 \pm 0.04^{\mathrm{c}}$ & $1.91 \pm 0.11^{\mathrm{e}}$ \\
\hline
\end{tabular}

Note: Mean value of three independent measurements \pm SD. Significant differences between treatment are indicated by different letter (ANOVA, $p<0.05)$.

$\Delta E$ and $\mathrm{BI}$ values depending on the size of the retort pouches are presented in Figures $6 \mathrm{a}$ and 6b, respectively. As the volume of the pouch decreased, $\Delta E$ tended to decrease and was similar with the tendency of $L, a$ and $b$ values. This was mainly due to the calculation of $\Delta E$, which required the $L, a$ and $b$ values. The changes of $L$, $a$ and $b$ values directly reflected the changes of $\Delta E$. BI also decreased as the volume of the pouch decreased. Generally, BI increased as $b$ increased and $L$ decreased. However, since $b$ contributed to BI more than $L$ or $a, \mathrm{BI}$ significantly decreased as the pouch volume decreased (Figure 6b). This result showed that the longer thermal processing time required as the pouch volume increased significantly changed the quality of the radish broth. The similar results have been published. Lee et al. ${ }^{[33]}$ investigated the color changes of radish extract at different temperatures from $110^{\circ} \mathrm{C}$ to $150^{\circ} \mathrm{C}$ at a constant thermal processing time. The $L$ value decreased and the $a$ and $b$ values increased as the thermal processing temperature increased. Since the thermal processing time was constant, the higher thermal processing temperature gave more energy to the sample and changed the color of the radish extract.

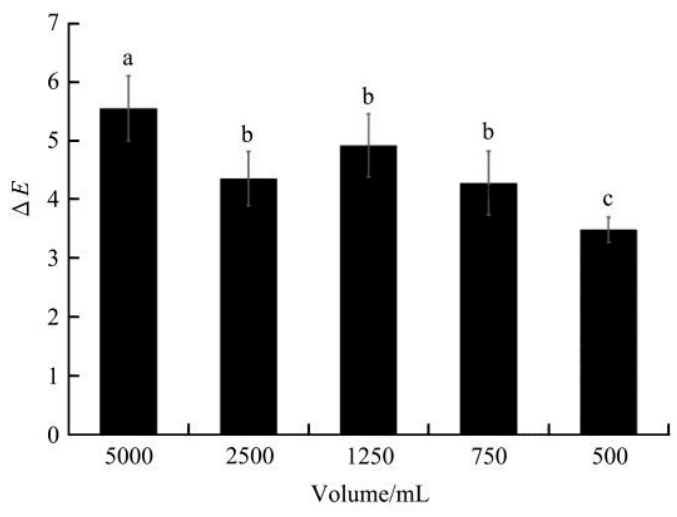

a. Total color difference

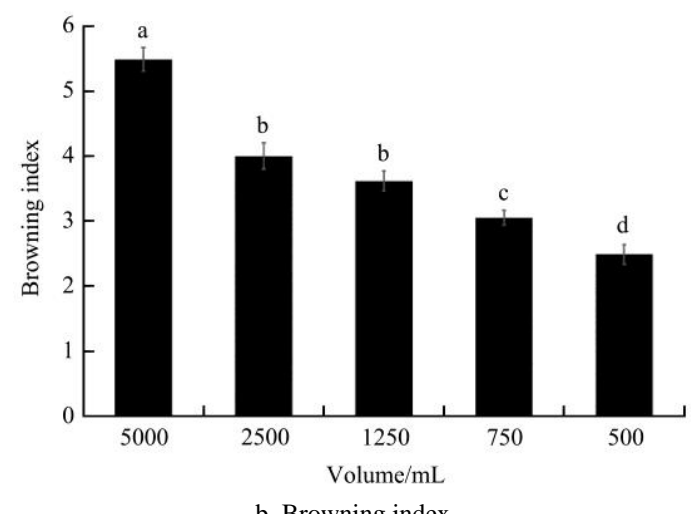

Note: Different letters on the bars of the same item indicate a significant difference $(p<0.05)$.

Figure 6 Changes in color value on the white radish broth with different pouch volumes

\subsection{Color changes after DSI}

The effect of thermal processing temperature of the DSI process on the color of radish juice was investigated (Table 4). $\quad L$ value did not show a significant difference between the control and others, as well as between thermally treated samples, while the $a$ and $b$ values showed a temperature dependence for all treatments. Both the lowest $a$ value and the highest $b$ value were found at $125^{\circ} \mathrm{C}$, which is the lowest temperature applied in the DSI process.

Table 4 Lab color value of the white radish broth from different direct steam injection sterilization temperatures

\begin{tabular}{cccc}
\hline & \multicolumn{3}{c}{ Color value } \\
\cline { 2 - 4 } Temperature $/{ }^{\circ} \mathrm{C}$ & $a$ & $b$ \\
\hline Control & $91.85 \pm 0.18^{\mathrm{a}}$ & $0.22 \pm 0.05^{\mathrm{a}}$ & $0.21 \pm 0.04^{\mathrm{d}}$ \\
125 & $91.58 \pm 0.41^{\mathrm{a}}$ & $-0.24 \pm 0.03^{\mathrm{d}}$ & $1.14 \pm 0.03^{\mathrm{a}}$ \\
130 & $91.67 \pm 0.32^{\mathrm{a}}$ & $-0.22 \pm 0.02^{\mathrm{c}}$ & $1.11 \pm 0.05^{\mathrm{b}}$ \\
135 & $91.76 \pm 0.65^{\mathrm{a}}$ & $-0.20 \pm 0.05^{\mathrm{b}}$ & $1.08 \pm 0.03^{\mathrm{c}}$ \\
\hline
\end{tabular}

Note: Mean value of three independent measurements \pm SD. Significant differences between treatment are indicated by different letter (ANOVA, $p<0.05$ ). 
The temperature dependence of $\Delta E$ and $\mathrm{BI}$ were calculated (Figures $7 \mathrm{a}$ and $7 \mathrm{~b}$, respectively). Samples packed in $500 \mathrm{~mL}$ pouches were chosen to compare the effect of the retort process with the DSI system, because the thermal processing times of the $500 \mathrm{~mL}$ samples were the shortest among the retorted samples. The $\Delta E$ of the DSI treated samples were significantly lower than that of the sample treated with the retort process, however there was no significant difference between the DSI treated samples. The $\Delta E$ difference between DSI treated samples and the control was directly due to the difference of $L$ values. BI values of DSI treated samples were higher than that of the control, but were significantly lower than retort processed samples. There was no significant difference of BI values between the DSI treated samples. The thermal processing time of DSI was $6.8 \mathrm{~min}, 2.24 \mathrm{~min}$ and $0.72 \mathrm{~min}$ at $125^{\circ} \mathrm{C}, 130^{\circ} \mathrm{C}$ and $135^{\circ} \mathrm{C}$, respectively. The thermal processing time of the retort process was $18.85 \mathrm{~min}$ for the $500 \mathrm{~mL}$ pouch. This directly demonstrated that the short thermal processing time from the DSI process minimized the quality changes of radish broth. It has been reported that the browning of white radish was caused by the activation of polyphenol oxidase (PPO) ${ }^{[2]}$. However, Goyeneche et al. $^{[34]}$ reported that $>90 \%$ of PPO was thermally inhibited at temperatures exceeding $90^{\circ} \mathrm{C}$. Since all the experiments in this study were conducted under high temperatures $\left(>90^{\circ} \mathrm{C}\right)$, the browning of the broth might not be due to the activation of PPO. It could be a non-enzymatic browning (NEB), which occurred in many food applications. Roux et al. ${ }^{[18]}$ applied DSI and ohmic heating for a liquid type of baby food and concluded that the browning at high temperatures was mainly due to the Maillard reaction. Another interesting observation was provided by Blake et al. ${ }^{[35]}$ They investigated the quality changes and the degree of sterilization of milk using a DSI and a heat exchanger. The DSI process showed a better sensory result and the browning of the DSI treated sample was lower than that of the heat exchanger treated samples. Zadow $^{[36]}$ reported similar findings. Our study also showed that the DSI treated sample lowered the browning of radish broth; this might be due to the short thermal processing time of the DSI process.

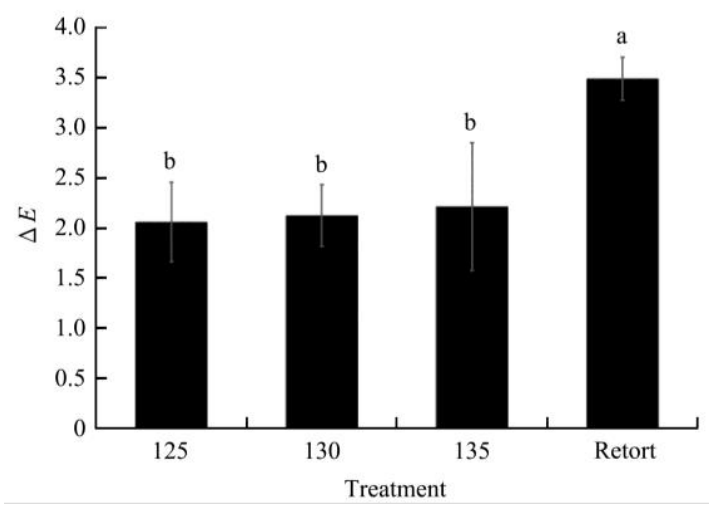

a. Total color difference

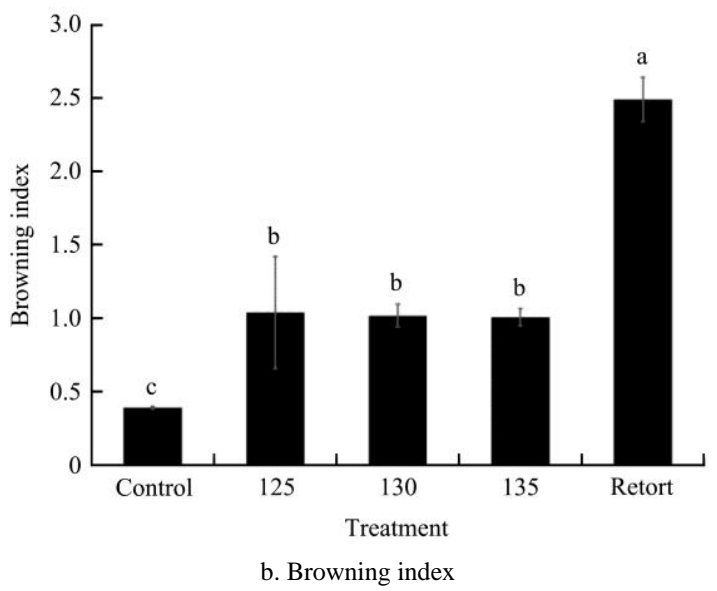

Note: Different letters on the bars of the same item indicate a significant difference $(p<0.05)$.

Figure 7 Changes in color value on the white radish broth with different treatment and temperature

\subsection{Sensory evaluations}

Sensory evaluations were performed for the DSI treated samples. Based on the measurement of $\Delta E$ and $\mathrm{BI}$, the retort treated samples were significantly different from those of DSI treated. However, those three DSI treated samples were not significantly different. The main purpose of the sensory test was to determine an optimum DSI condition among three DSI conditions applied in this study. The mean values of sensory scores including color, odor, taste, texture and total preference are shown in Table 5. The scores for color at different temperatures ranged between 4.60 and 4.80 with no significant difference. It was agreed with the results of color measurements. While the scores of texture, taste and total preference did not show a significant difference, the odor score from $125^{\circ} \mathrm{C}$ treated samples was significantly higher than that of higher temperatures. A somewhat burnt smell was noted from the samples treated at $130^{\circ} \mathrm{C}$ and $135^{\circ} \mathrm{C}$. Yuan and Chang ${ }^{[16]}$ reported the effects of DSI processing on the flavor of soy milk by 
comparing it with conventional heat treatments. The DSI generated more preferable flavor components than that of other heat treatments. However, in this case, as the temperature applied in DSI increased, DSI might produce negative flavor components. The results showed that the optimum heat treatment for the radish broth from the DSI was $125^{\circ} \mathrm{C}$ in terms of quality changes and the degree of sterilization.

Table 5 Average sensory scores of the radish broth from different direct steam injection sterilization temperatures

\begin{tabular}{cccc}
\hline & \multicolumn{3}{c}{ Temperature/ ${ }^{\circ} \mathrm{C}$} \\
\cline { 2 - 4 } & 125 & 130 & 135 \\
\hline Color & $4.60 \pm 0.85^{\mathrm{a}}$ & $4.80 \pm 0.97^{\mathrm{a}}$ & $4.67 \pm 1.07^{\mathrm{a}}$ \\
Odor & $5.54 \pm 0.64^{\mathrm{a}}$ & $4.67 \pm 1.11^{\mathrm{b}}$ & $4.53 \pm 0.83^{\mathrm{b}}$ \\
Texture & $5.53 \pm 0.85^{\mathrm{a}}$ & $5.40 \pm 1.16^{\mathrm{a}}$ & $5.33 \pm 0.67^{\mathrm{a}}$ \\
Taste & $5.00 \pm 0.88^{\mathrm{a}}$ & $4.94 \pm 1.23^{\mathrm{a}}$ & $4.94 \pm 0.74^{\mathrm{a}}$ \\
Overall acceptability & $5.13 \pm 0.82^{\mathrm{a}}$ & $4.93 \pm 0.74^{\mathrm{a}}$ & $4.87 \pm 0.82^{\mathrm{a}}$ \\
\hline Note: Mean value of three independent measurements \pm SD. Significant \\
differences between treatment are indicated by different letter (ANOVA, $p<0.05$ )
\end{tabular}

\section{Conclusions}

The degree of sterilization and the color changes of the white radish broth were evaluated with a retort process and a DSI process. For the retort process, the pouch volumes of $500 \mathrm{~mL}, 750 \mathrm{~mL}, 1250 \mathrm{~mL}$ and 5000 $\mathrm{mL}$ were used to investigate the effects of different dimensions on the thermal processing time and the associated quality changes. As the retort pouch volume increased, the time to reach target $F_{0}$-value increased. However, the DSI treatment showed 0.36-fold processing time compared with the smallest pouch volume $(500 \mathrm{~mL})$ among the retort pouches. While the $L$ value did not show a significant difference, as the volume of the retort pouch increased, the $a$ and $b$ values significantly increased. The BI increased as the pouch volume increased, with a maximum value of $5.49 \pm 0.18$ in the $5000 \mathrm{~mL}$ pouch and a minimum value of $2.49 \pm 0.15$ in the $500 \mathrm{~mL}$ pouch. The BI of DSI treated samples did not show a significant difference with differing processing temperatures, but the BI was significantly lower than that of the retorted product. This confirms that DSI is an effective method to produce radish broth while minimizing the browning. The sensory evaluation of DSI treated samples with different thermal processing temperatures showed an interesting result that the samples treated with a lower thermal processing temperature of DSI showed significantly high scores in odor, although the color scores showed no differences. Therefore, the optimum thermal processing temperature of DSI was determined to be $125^{\circ} \mathrm{C}$.

\section{Acknowledgments}

This work was supported by Korea Institute of Planning and Evaluation for Technology in Food, Agriculture, Forestry and Fisheries (IPET) through High Value-added Food Technology Development Program, funded by Ministry of Agriculture, Food and Rural Affairs (Grant No. 314047-2). This study has been worked with the support of a research grant of Kangwon National University in 2016.

\section{[References]}

[1] Byun G I, Kim D J, Choi S K. Purchase accommodation attitude of commercial stock merchandise-focused on cuisiniers of deluxe hotels. Culi Sci \& Hos, 2008; 14: 115-127.

[2] Andi N F R, Ohta M, Li Y, Nakatani K, Hayashi N, Fujita S. Purification and characterization of polyphenol oxidase from Japanese radish (Raphanus sativus L.) root. J Jpn Ass Food Pres Scientists, 2007; 35(5): 233-240.

[3] Goyeneche R, Di Scala K, Roura S. Biochemical characterization and thermal inactivation of polyphenol oxidase from radish (Raphanus sativus var. sativus). LWT-Food Sci Technol, 2013; 54(1): 57-62.

[4] Lee S H, Hwang I G, Lee Y R, Joung E M, Jeong H S, Lee H B. Physicochemical characteristics and antioxidant activity of heated radish (Raphanus sativus L.) extracts. J Korean Soc Food Sci Nutr, 2009; 38(4): 490-495.

[5] Teixeira A A, Tucker G S. On-line retort control in thermal sterilization of canned foods. Food Control, 1997; 8(1): 13-20.

[6] Patras A, Tiwari B K, Brunton N P, Butler F. Modelling the effect of different sterilization treatments on antioxidant activity and color of carrot slices during storage. Food Chem, 2009; 114(2): 484-491.

[7] Lespinard A R, Mascheroni R H. Influence of the geometry aspect of jars on the heat transfer and flow pattern during sterilization of liquid foods. J of Food Process Eng, 2011; 35(5): 751-762.

[8] Lespinard A R, Bambicha R R, Mascheroni R H, Quality parameters assessment in kiwi jam during pasteurization. Modelling and optimization of the thermal process. Food 
and Bioprod Process, 2012; 90(4): 799-808.

[9] Singh A, Singh A P, Ramaswamy H S. Effect of processing conditions on quality of green beans subjected to reciprocating agitation thermal processing. Food Res Int, 2015; 78: 424-432.

[10] Hong Y K, Uhm J T, Yoon W B. Using numerical analysis to develop and evaluate the method of high temperature sous-vide to soften carrot texture in different-sized packages. J Food Sci, 2014; 79(4): E546-561.

[11] Yim S K, Sohn K H. Effects of sterilization temperature on the quality of carrot purees. Food Sci Biotechnol, 2014; 13(2): 141-146.

[12] Lespinard A R, Arballo J R, Taus F J. Multi-Objective optimization of the pasteurization process of pumpkin cubes packaged in glass Jars. Int $\mathrm{J}$ of Food Eng, 2015; 11(5): 679-689.

[13] García-Parra J, González-Cebrino F, Delgado J, Cava R, Ramírez R. High pressure assisted thermal processing of pumpkin purée: effect on microbial counts, color, bioactive compounds and polyphenoloxidase enzyme. Food Bioprod Process, 2016; 98: 124-132.

[14] Dill C W, Roberts W M, Aurand L W. Poduction of sulfur compounds in skim milk heated by direct steam injection. J Dairy Sci, 1962; 45(11): 1332-1335.

[15] Hui YH. Ch108 heat transfer. Handbook of food science, technology, and engineering (Vol. 149). Florida: CRC Press. 2006; pp. 106-108.

[16] Yuan S H, Chang S K C. Selected odor compounds in cooked soymilk as affected by soybean materials and direct steam injection. J food Sci, 2007; 72(7): S481-486.

[17] van Asselt A J, Sweere A P J, Rollema H S, de Jong P. Extreme high-temperature treatment of milk with respect to plasmin inactivation. Int Dairy J, 2008; 18(5): 531-538.

[18] Roux S, Courel M, Birlouez-Aragon I, Municino F, Massa M, Pain J P. Comparative thermal impact of two UHT technologies, continuous ohmic heating and direct steam injection, on the nutritional properties of liquid infant formula. J Food Eng, 2016; 179: 36-43.

[19] van Loey A, Fransis A, Hendrickx M, Maesmans G, Tobback P. Kinetics of quality changes of green peas and white beans during thermal processing. J Food Eng, 1995; 24(3): 361-377.

[20] Ovissipour M, Rasco B, Tang J, Sablani S S. Kinetics of quality changes in whole blue mussel (Mytilus edulis) during pasteurization. Food Res Int, 2013; 53(1): 141-148.

[21] Hou L X, Ling B, Wang S J. Kinetics of color degradation of chestnut kernel during thermal treatment and storage. Int J Agric Biol Eng, 2015; 8(4): 106-115.

[22] Pflug I J, Odlaug T E. A review of $z$ and $F$ values used to ensure the safety of low-acid canned food. Food Technol-Chicago, 1978; 32: 63-70.
[23] Ramaswamy H S, Marcotte M. Marcotte Food processing — Principles and application. Florida: CRC Press. 2006.

[24] Holdsworth $S$ D. Principles of thermal processing: Sterilization R. Simpson (Ed.), Engineering Aspects of Thermal Food Processing. Florida: CRC Press. 2009. pp. 3-11.

[25] Anderson W A, McClure P J, Baird-Parker A C, Cole M B. The application of a log-logistic model to describe the thermal inactivation of Clostridium botulinum $213 \mathrm{~B}$ at temperatures below $121.1^{\circ} \mathrm{C}$. J Appl Bacteriol, 1996; 80(3): 283-290.

[26] Thulukkanam K. Shell and tube heat transfer design. Heat exchanger design handbook. Florida: CRC Press. 2013; pp. 329-336.

[27] Maskan M. Kinetics of colour change of kiwifruits during hot air and microwave drying. J Food Eng, 2001; 48(2): $169-175$.

[28] Lawless H T, Heymann H. Sensory evaluation of food principles and practices. Chap. 6, $2^{\text {nd }}$ ed. New York: Springer. 2010. pp. 125-145.

[29] Koo B Y, Park S J, Byeon Y R, Son S H. Heat penetration characteristics and keeping quality of retort pouched curry. Korean J Food Sci Technol, 1993; 25(1): 63-68.

[30] Richard P, Durance T D, Sandberg G M M, A Computer simulation of thermal sterilization of canned foods with sub-freezing initial temperatures. Can I Food Sci Tech J, 1991; 24(1): 95-98.

[31] Innings F, Hamberg L. Steam condensation dynamics in annular gap and multi-hole steam injectors. Procedia Food Sci, 2011; 1 : 1278-1284.

[32] Karayannakidis P D, Apostolidis E, Lee C M. Comparison of direct steam injection and steam-jacketed heating in squid protein hydrolysis for energy consumption and hydrolysis performance. LWT-Food Sci Technol, 2014; 57(1): 134-140.

[33] Lee S H, Hwang I G, Lee Y R, Joung E M, Jeong H S, Lee H B. Physicochemical characteristics and antioxidant activity of heated radish (Raphanus sativus L.) Extracts. J Korean Soc Food Sci Nutr, 2009; 38(4): 490-495.

[34] Goyeneche R, Scala K D, Roura S. Biochemical characterization and thermal inactivation of polyphenol oxidase from radish (Raphanus sativus var. sativus). LWT-Food Sci Technol, 2013; 54(1): 57-62.

[35] Blake M R, Weimer B C, McMahon D J, Savello P A. Sensory and microbial quality of milk processed for extended shelf life by direct steam injection. J Food Protect, 1995; 58(9): 1007-1013.

[36] Zadow J G. Studies on the ultraheat treatment of milk. II. Measurement of the products of browning reactions as influenced by processing and storage. Austn J Dairy Technol, 1970; 25(3): 123-126. 